\title{
Guidelines for the Development and Improvement of Universal Access Systems for Blind Students
}

\author{
David Arnim ${ }^{1}$, Benito S. Piuzzi ${ }^{1}$, Chang S. Nam ${ }^{1}$, and Donghun Chung ${ }^{2}$ \\ ${ }^{1}$ Department of Industrial Engineering \\ University of Arkansas \\ 4207 Bell Engineering Center, Fayetteville, AR 72701, U.S.A \\ \{darnim, bpiuzzi, cnam\} @uark. edu \\ ${ }^{2}$ School of Communication \\ Kwangwoon University \\ 447-1 Wolgye-Dong, Nowon-Gu, Seoul Korea 139-70a \\ donghunc@uark. edu
}

\begin{abstract}
This paper describes a study conducted to develop a set of interface design principles and guidelines that can be used to develop and improve universal access systems for the visually impaired, such as Haptic Audio Virtual Environments (HAVEs). Over the last few decades, user interface systems have advanced to allowing users to interact with computational systems physically, perceptively, and conceptually. However, this process has also left blind and partially blind users unable to access such new technologies. It is also true that there are currently only limited methods for presenting information non-visually and these do not provide an equivalent speed and ease of use to their graphical counterparts. Comprehensible design principles and guidelines addressing the needs of blind users should be helpful when developing universal access systems, such as haptic audio virtual environments that use multiple sensory modalities to present information.
\end{abstract}

Keywords: universal access, assistive technology, design principles and guidelines.

\section{Introduction}

Blind and partially blind users have been left behind in the technology development because of the increase of icon rich computer environments [1]. In addition, there are currently only limited methods for presenting information non-visually and these do not provide an equivalent speed and ease of use to their graphical counterparts [2]. Human computer interaction (HCI) frequently elicits the image of a fully sighted user, periodically responding to visual cues as they are presented [3], thus blind and partially blind users have not been given the proper opportunities to access these systems.

According to the American Foundation for the Blind, approximately $45 \%$ of individuals with severe visual impairment or blindness have a high school diploma, compared to $80 \%$ among fully sighted individuals. Among high school graduates, those with severe visual impairment or blindness are about as likely to have taken 
some college courses as those who were sighted, but they are less likely to have graduated. There are also about 10 million blind and partially blind people in the United States, from this number only 1.5 million use a computer. These numbers are enough evidence to start thinking of a definite way to help blind and partially blind users. Therefore, it is now important to look for ways to turn this numbers around and integrate visually impaired people into this new century full of technology.

The primary objective of this paper is to introduce design principles and guidelines for the development and improvement of universal access systems (e.g., haptic audio virtual environments) for the blind, with a main focus in developing science and engineering learning environments for visually impaired students.

\section{Universal Access Systems for Blind Users}

Visually impaired users have had to rely on verbal based feedback from systems such as JAWS (Job Access With Speech), ZoomText, and closed circuit televisions (CCTV). JAWS main advantage is its outputs to refreshable Braille displays, but it is limited to the use of Windows only and does not help the user interact with the actual graphical interface or its orientation within the screen. Zoomtext is a tool that helps partially blind users enlarge texts by increasing the font size. It is a very useful tool but it can only be used with texts and pictures and does not assist the user in interacting with graphics. CCTV changes the spectrum of colors of a document, assisting color blind users in interacting with texts and pictures. Although these elements are highly effective in current teaching methods, they do not contribute much in the development and understanding of some scientific and/or engineering concepts to blind students, such as Gravity or Thermodynamics which require multiple sensory modalities to present.

Some of the early research and experimentation also includes the development of the Z-Glove and DataGlove [4]. These systems allow visually impaired people to feel relieves and shapes of certain virtual simulated objects. There are not significant differences among these two systems; however their way of processing the information is different. Their main advantage is clearly the ease of sensing shapes and surfaces of objects that can be simulated, however these gloves do not assist to identify colors and pictures and there were certain hand movements that the computer could not identify. TDraw [5] has also been developed to help blind people draw pictures. Other research/experiments engage the concepts of text edition. MAGNEX is a general purpose full screen text editor which incorporates features intended to make it especially useful to individuals with a wide range of visual impairments [6]. Magnex was developed to meet two objectives: 1) to provide powerful, full screen, general purpose editing capabilities, and 2) to make these facilities available and comfortable to use for as broad a community as possible of visually impaired people. Within its options, the user is able to change the font size, background colors etc. Although this tool is a big step towards meeting visually impaired people needs, it still lacks of a variety of options that allow the user to customize the text. 
Researches have been trying to implement systems and tools that satisfy visually impaired needs. However, it has always been difficult to follow a standardized set of guidelines or rules that can be used to develop systems that can meet the blind and/or partially blind user's needs.

\section{Interface Design Principles and Guidelines for Blind Users}

Three schools for the blind were contacted to obtain information from: Texas School for the Blind and the Visually Impaired, Oklahoma School for the Blind, and Arkansas School for the Blind.

The guidelines are divided in six major categories: GUIDING, REFERENCE, BOUNDARIES, USING SOUND, USER LEARNING SUPPORT, and INTERACTION WITH THE SYSTEM. From our previous contacts at the schools a second survey was developed to gauge the usefulness of our new guidelines. We asked our respondents to rank the effectiveness of each guideline proposed. From the survey we found that one of the methods that seem to be the most useful was the one that dealt with the system set-up. These included icon size, orientation, and reference points that the user can easily find. Some examples of the guidelines proposed are explained in more detail.

\subsection{Category 1: Guiding}

The Guiding guidelines address the concern of button or icon size and position within the GUI. Using these guidelines efficiently would allow the blind and partially blind user to navigate his or her way within the system.

Table 1. Examples of Guiding Guidelines and Justification

\begin{tabular}{|c|l|l|}
\hline Category & \multicolumn{1}{|c|}{ Guideline } & \multicolumn{1}{|c|}{ Justification } \\
\hline \multirow{6}{*}{ Guiding } & $\begin{array}{l}\text { Target points should be larger than } \\
\text { normal }\end{array}$ & $\begin{array}{l}\text { Large icons are easier to access } \\
\text { and find than smaller ones }\end{array}$ \\
\cline { 2 - 3 } & $\begin{array}{l}\text { Choose manipulation tool that best } \\
\text { fits the application need }\end{array}$ & $\begin{array}{l}\text { If accurate targeting is required a } \\
\text { pen tool may be easier to use than } \\
\text { a mouse or joystick, etc. }\end{array}$ \\
\cline { 2 - 4 } & $\begin{array}{l}\text { Minimal \# of targets/buttons used } \\
\text { to screen at any one time }\end{array}$ & $\begin{array}{l}\text { Fewer icons will result in less } \\
\text { confusion to the user. }\end{array}$ \\
\cline { 2 - 4 } & $\begin{array}{l}\text { Use a 'gravitational force' whenever } \\
\text { possible to help pull the cursor into } \\
\text { the button }\end{array}$ & $\begin{array}{l}\text { Faster target acquisition will be } \\
\text { generated. }\end{array}$ \\
\cline { 2 - 3 } & \begin{tabular}{l} 
Use a linear set-up of icons \\
\cline { 2 - 3 }
\end{tabular} & $\begin{array}{l}\text { Speech activation program } \\
\text { It is easier for a user to navigate } \\
\text { through the icons. }\end{array}$ \\
\cline { 2 - 3 } & $\begin{array}{l}\text { It is a system similar to that used } \\
\text { by high end cell phones to access } \\
\text { certain programs. }\end{array}$ \\
\cline { 2 - 3 } & $\begin{array}{l}\text { Verbal navigation system (JAWS) } \\
\text { over or selecting a certain option. }\end{array}$ \\
\hline
\end{tabular}


With larger than normal target points blind users can locate buttons easier, because the probability of overshooting an icon or not recognizing the 'gravitational' force can be minimized. Choosing the proper manipulation tool is essential to the user moving around the computer interface. If more precision is needed, then a stylus type tool would be a better fit than a standard mouse. By minimizing the number of target points on the screen at any one time there will be a lower chance that the blind user will get confused or lost. A gravitational force would allow the user to be pulled into a button when he or she was within the gravity field. This force would be similar to a snap, but would be much gentler. For example, if the user was within a predetermined distance of a button then the user would feel the manipulation device being pulled into an area. With the use of a JAWS system, the user would also be prompted what icon/button they were approaching.

A linear set-up of icons would greatly improve the users targeting ability. Some systems use a circular set-up of icons because sighted users can make faster acquisition of buttons. For a blind or low vision user it would be very difficult to determine the difference of position between a button at twelve o'clock and one at one o'clock. When using force feedback studies have shown that a linear set-up will result in faster target acquisition. With a speech activation program the user would be able to pull up commonly used programs and functions easier. By activating the speech system with a key stroke the user could access a word processing program easily and then proceed to either type, or use the speech with voice recognition to type it as the user speaks. When the JAWS system is used properly the user would be alerted to the location of their pointing tool.

\subsection{Category 2: Reference}

The Reference guideline addresses the need to have a GUI set-up that is easy to navigate. An effective reference system will aid the blind and partially blind user in being able to use the system as effectively as possible.

Table 2. Examples of Reference Guidelines and Justification

\begin{tabular}{|c|l|l|}
\hline Category & \multicolumn{1}{|c|}{ Guideline } & \multicolumn{1}{|c|}{ Justification } \\
\hline \multirow{3}{*}{ Reference } & All reference points should be easy to find & $\begin{array}{l}\text { Corners and edges are well } \\
\text { defined. }\end{array}$ \\
\cline { 2 - 3 } & $\begin{array}{l}\text { Reference system should not be changed } \\
\text { unnecessarily }\end{array}$ & $\begin{array}{l}\text { Standard locations are easier to } \\
\text { find. }\end{array}$ \\
\cline { 2 - 3 } & Pointer tool will move along a groove & $\begin{array}{l}\text { A grooved path would help find } \\
\text { targets on a grid. }\end{array}$ \\
\hline
\end{tabular}

Reference points pertain to common areas such as corners and boundaries of windows. By keeping things in a linear set-up these areas would be easy to find for a user using a haptic device. By using a fixed reference system the user would only need to remember the specific areas of a window. Some common areas would include an exit button, or save button [7]. It is common practice now to use a system such as 
this. For example Windows ${ }^{\circledR}$ uses a system like this in all of their Microsoft Office ( ) programs. The exit button, minimize, and restore buttons are in the upper right corner, where the File button is always in the upper left corner. Having the pointer move along a grooved path would help the user navigate through a linear set-up of icons. The user would be restricted to moving in ninety-degree directions. This would be beneficial when using a linear set-up.

\subsection{Category 3: Boundaries}

The Boundaries guidelines address the need to have a system set up to restrict the blind and partially blind user to a certain area, which can help the users 'feel' their way within a system.

Table 3. Examples of Boundaries Guidelines and Justification

\begin{tabular}{|c|l|l|}
\hline Category & \multicolumn{1}{|c|}{ Guideline } & \multicolumn{1}{c|}{ Justification } \\
\hline \multirow{5}{*}{ Boundaries } & $\begin{array}{l}\text { Manipulation on the 'mouse pad' } \\
\text { directly corresponds to motion on the } \\
\text { screen }\end{array}$ & $\begin{array}{l}\text { This will help the user navigate to } \\
\text { specific points on the screen. }\end{array}$ \\
\cline { 2 - 3 } & Instead use rounded corners and sides & $\begin{array}{l}\text { Sharp edges are difficult to feel } \\
\text { with a haptic device. }\end{array}$ \\
\cline { 2 - 3 } & Add ridges to the window frame. & $\begin{array}{l}\text { Ridges would help to 'confine' the } \\
\text { user to a certain area until they } \\
\text { were ready to move into another. }\end{array}$ \\
\cline { 2 - 3 } & $\begin{array}{l}\text { Ridges also added to icons to prevent } \\
\text { 'over shooting' the icon }\end{array}$ & $\begin{array}{l}\text { This will help in identification of } \\
\text { acquisition. }\end{array}$ \\
\hline
\end{tabular}

Having a system where the movement on the surface directly correlates to movement on the screen would allow the user to find the reference points easily. By making the upper left corner of the surface correspond to the upper left corner on the screen or the center of the pad be the center of the screen, the user could find the exit button easily. Current systems do not have such a boundary system in place. Rounded corners on buttons or icons are easier to feel with current haptic devices than sharp edges. This will allow the user to determine a button or icon [8]. By adding ridges to window frames if multiple windows are on the screen at one time will help to keep the user in one area. If the user did need to cross over to a different window then the user could apply a set force to jump over the border to the adjacent window frame. If the user knows a certain window is open then an Alt-Tab function or something similar can be used to swap windows. In this case the addition of edges to open windows would help the user identify the presence of open windows. Ridges can also be added to the buttons or icons so the user will feel like they are dropping into a hole or rising up onto a button [9]. The ridges, when coupled with the gravitational force and JAWS, would help the user find buttons. It will also help the user to determine if an option is engaged. For example, if the user were to 'fall' into a hole then it could be understood that the option is in use. 


\subsection{Category 4: Using Sound}

The Using Sound guidelines address the use of sound for navigation in a system. When used properly the addition of sounds can greatly enhance the blind and partially blind user's computer experience.

Table 4. Examples of Using Sound Guidelines and Justification

\begin{tabular}{|c|l|l|}
\hline Category & \multicolumn{1}{|c|}{ Guideline } & \multicolumn{1}{c|}{ Justification } \\
\hline \multirow{5}{*}{ Using Sound } & $\begin{array}{l}\text { Take care in associating tones } \\
\text { with certain options }\end{array}$ & $\begin{array}{l}\text { It is recommended not to use sounds } \\
\text { that can be mistaken for errors or other } \\
\text { universally accepted tones. }\end{array}$ \\
\cline { 2 - 3 } & $\begin{array}{l}\text { Use pitch only as a ranking } \\
\text { device }\end{array}$ & $\begin{array}{l}\text { Using pitch will help the user identify } \\
\text { ranks of systems. }\end{array}$ \\
\cline { 2 - 3 } & Stereo sound & $\begin{array}{l}\text { It will help the user determine left-to- } \\
\text { right movement or vice versa. }\end{array}$ \\
\cline { 2 - 3 } & $\begin{array}{l}\text { Non-Verbal sounds can be used } \\
\text { to represent actions or } \\
\text { information about objects }\end{array}$ & $\begin{array}{l}\text { It can indicate whether an icon is un- } \\
\text { usable or is in use. }\end{array}$ \\
\cline { 2 - 3 } & $\begin{array}{l}\text { Use textual/verbal feedback for } \\
\text { icons and buttons as well as } \\
\text { menus, title bars, etc... }\end{array}$ & $\begin{array}{l}\text { When used sparingly, the system will } \\
\text { vocalize the button/icon the user is } \\
\text { about to access. }\end{array}$ \\
\hline
\end{tabular}

Because certain tones can mean specific things, it is desirable when using sounds to use those that can be mistaken for something else. For example, in most systems, a simple 'ding' sound is used whenever an option is unavailable or an error has been caused. This 'ding' sound should not be used in conjunction with any other option. When using the concept of pitch, the pitch should be restricted to the soprano and bass tones. Using pitch will help the user to increase or decrease an option [10], for example if the user wishes to change the font size of text for a document being produced. A tone that gets higher in pitch would alert the user to an increase in font size, where a bass tone would alert the user to the opposite. If a low vision user needed to resize a window from left-to-right or vice versa, a stereo sound would aid the user in his or her task [10]. The stereo tones could also be used to help the user determine which side of the window he or she is in. Tones that indicate icons being usable or unusable are already in use today in computer systems. It would be beneficial to use such tones to help the user determine if a button he or she has selected is usable or if an error is caused. Using a system such as JAWS would help when the user has encountered a button or icon. The system would tell the user what button he or she is over and then they would be able to decide whether or not they wished to select the option or move on to the next one. Great care should be taken however in using sounds to help the user. If there are too many sounds, or if multiple sounds go off at once it can be confusing to the user. Therefore it is suggested that the user be able to turn off all sounds, or to choose what sounds to turn off or on. 


\subsection{Category 5: Interaction with System}

The Interaction with System guidelines relate to the importance of what happens to the computer system if it is left idle, or if the blind and partially blind user needs to correct a mistake.

Table 5. Examples of Interaction with System Guidelines and Justification

\begin{tabular}{|c|l|l|}
\hline Category & \multicolumn{1}{|c|}{ Guideline } & \multicolumn{1}{c|}{ Justification } \\
\hline \multirow{4}{*}{$\begin{array}{c}\text { Interaction } \\
\text { with System }\end{array}$} & $\begin{array}{l}\text { If cursor idle for set amount of time, } \\
\text { reset to default position }\end{array}$ & $\begin{array}{l}\text { If user knows starting point then it } \\
\text { will be easier to find buttons/icons }\end{array}$ \\
\cline { 2 - 4 } & $\begin{array}{l}\text { Make it easy to go back if mistake is } \\
\text { made }\end{array}$ & $\begin{array}{l}\text { It allows the user to have one key } \\
\text { access to go back. }\end{array}$ \\
\cline { 2 - 3 } & \begin{tabular}{l} 
Allow the user to turn off verbal \\
commands or force if not desired \\
\cline { 2 - 3 }
\end{tabular} & $\begin{array}{l}\text { If sounds are not needed, they may } \\
\text { be counter productive to the user. }\end{array}$ \\
\cline { 2 - 3 } & $\begin{array}{l}\text { Use target crosshairs as the cursors } \\
\text { for partially sighted users }\end{array}$ & $\begin{array}{l}\text { It helps the user to accurately see } \\
\text { where they are pointing if a typical } \\
\text { pointer arrow is too hard to see. }\end{array}$ \\
\hline
\end{tabular}

By allowing the cursor to reset to a default position the user would know where he or she is starting out. If the system is using a direct manipulation model, then the user can know exactly where on the screen the pointer is. For example, the cursor may reset to the center of the screen, when this happens the user would be aware of such a move and could move back to the previous spot, or continue working on something else. If the user were to make a mistake in the process it is beneficial to allow the user to go back to a previous screen or set-up with a key stroke or key command. For low vision users this would be helpful if they realize they made a mistake in a program. By using the go-back method, the user could start over from the spot just before the mistake was made. Multiple undos could be used to undo multiple commands if needed. If the user is not completely blind and can still see a computer screen with the use of a system to enlarge the screen the ability to turn off force feedback or verbal cues may be required. Doing so would allow the user to navigate through the system without those tools. The quick key functions would allow the user to access functions such as save, exit, undo, or print easily. Although in use by all computer systems, they should be kept in the new systems to help make manipulation of the system easier. In some instances, low vision users are unable to see a regular pointer tool, or it is too large to accurately pick an option. It is recommended to use a cross hairs system so that the target is identified by two lines that intersect over an area. The cross hair system would be useful when coupled with the screen being laid out in a grid pattern and the cross hairs moving along a grooved path.

\section{Discussion and Conclusions}

Research and experiments that have been done during the last decade have the common goal of assisting visual impaired people; however there has not been much 
research to define a standardized set of guidelines that will assist in the development of new systems and tools. We believe that a strong set of design principles and guidelines can set the foundation for future researches that can assist visually impaired people interaction with technology.

\subsection{Interviews and Surveys}

Based on interviews and surveys with students and instructors at various blind institutions, this study showed that there is an interest in using haptic technology to help the blind and partially blind user. Most of the people interviewed felt that a 'gravitational' force would be a great benefit to target acquisition. The force should be gentle enough however as to not 'snap' the user onto the button, rather the user should feel like he or she is being guided into position. Another guideline well liked by those interviewed is a linear set-up of icons. The linear set-up would help the users navigate through the system without trying to figure out a circular set-up. With a circular set-up, depending on the number of icons, there would be a certain degree the user would have to move in an arc to find the next button. With the linear set-up the user would only need to be worried about left to right movement, or up and down. However, one area that may not be suitable for some users, or confusing to others would be the use of sounds: whether it is monophonic or stereo sounds. Those interviewed stated that it may be confusing or cause more harm than good. In dealing with sounds, the students and instructors alike did feel that keeping verbal feedback for icons in conjunction with the 'gravitational' force would be very helpful. An existing system such as JAWS would be adequate to handle this requirement.

\subsection{Science Learning for Visually Impaired and Blind Students}

As a proof-of-concept that our interface design principles and guidelines can make a significant impact, we introduce a haptic virtual learning environment we developed to help science learning for visually impaired students, demonstrating how these principles and guidelines have been applied [11].

The Individuals with Disabilities Education Act (IDEA, 1975) require that students with disabilities receive full access to education. However, visually impaired and blind students are not adequately accommodated in science instruction [12]. For example, $38 \%$ of students with special needs hardly receive any instruction in science and $90 \%$ of science teachers who teach these special education students often employ textbook-oriented teaching [13]. Therefore, how to increase the participation of students with disabilities, especially those with visual impairments in science education is a critical issue. We suggest that haptic force/tactile perception, combined with hearing and more importantly additional thermal sense [14], can be a very important perceptual mechanism for the visually impaired and the blind, because much of the blind's world is mapped through their haptic senses [15].

A haptic virtual learning environment was developed to help science learning for visually impaired and blind students, a learning system in which science education could be made accessible to both visually impaired students and their teachers [11]. For a learning application for science concepts, the temperature concept was chosen. Figure 1 shows a part of the learning scenario on the temperature concept used to 
develop the application, which was adopted from the Physics-2000 Website. Based on learning scenarios, a haptic virtual learning environment was developed in which the user can control the temperature of an object, see atoms' random movements with different speed depending on the object's temperature, and feel the warmth or coolness of the object and the corresponding speed of the atoms simultaneously.

- We all know that some things feel hot, and others cold, but is there more to temperature than that?

- When an object feels hot, the atoms inside it are moving fast in random directions, and when it feels cold, they are moving slowly. Our body interprets that random atomic motion into what we feel as hot and cold.

(a) An example of learning scenario

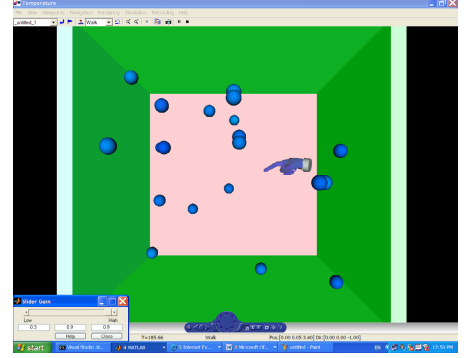

(b) Temperature application

Fig. 1. HAVE temperature application

Atoms (represented as spheres in Figure 1b) speed up or slow down as the temperature is changed. Students can feel the atoms' speed in the form of the force as they put their tip (represented as a pointing-hand) into the box. The box's background color also becomes the darker red to indicate the temperature change. The higher the velocity of the atoms the more hits and the stronger forces are sensed. With realistic sensations (e.g., changes in color, speed, force, temperature) of the scientific concept, this application will allow students to better understand that heat energy depends on the speed, the number, and the type of particles in an object, as well as that temperature does not depend on the size or type of the object. Students will also be allowed to manipulate several variables (e.g., temperature, the number of particles, etc.), and to see and feel what is happening as they change them.

With ridges added to the area where the atoms are the user would be able to confine the search for atoms to that area. For the user to navigate outside of the box, he or she would apply a force to break over to the control panel where the JAWS system would alert them to entering the area. The user could also use a quick key function that would allow them to automatically snap to the control panel. On the control panel the buttons would be laid out in such a fashion as to adhere to the guidelines presented. With a linear set-up and sufficient size and spacing the user could change the size of the atoms, the rate at which the temperature is increasing, starting and stopping, and any other options that would be required for such a system. The linear set-up would also allow the user to navigate left-to-right or vice versa, the gravitational force would help pull the user into the adjacent button, where JAWS would tell the user what function the button related to. By using pitch the user would be able to increase the size of the atoms (a soprano sound would indicate a larger size), the user could also decrease the temperature change rate (a bass tone would indicate such a change). An easy to use quick key function could then be used to reset the pointer tool into the box where the atoms are and another key function would start 
the process. The user would then be free to explore the environment and feel the heat and force changes present in the program.

\section{References}

1. Carneiro, M.M., Velho, L.: Assistive Interfaces for the Visually Impaired Using Force Feedback Devices and Distance Transforms. Info. Tech. and Disab. E J. (2004)

2. Brewster, S.A., Pengelly, H.: Visual Impairment, Virtual Reality and Visualisation. In: Proc. of the First International Workshop on Usability Evaluation for Virtual Environments, pp. 24-28. British Computer Society, Leicester, UK (1998)

3. Jacko, J., Sears, A.: Designing Interfaces for an Overlooked User Group: Considering the Visual Profiles of Partially Sighted Users. In: Third Annual ACM Conference on Assistive Technologies, pp. 75-77 (1998)

4. Zimmerman, T., Lanier, J., Blanchard, C., Bryson, S., Harvill, Y.: A Hand Gesture Input Device. In: Proc. of the Conference of Human Factors in Computing Systems and Graphics Interface, ACM SIGCHI, Toronto, pp. 189-192 (1987)

5. Kurze, M.: TDraw: A Computer-Based Tactile Drawing Tool for Blind People. In: International ACM Conference on Assistive Technologies, pp. 131-138 (1996)

6. Vener, A.R., Glinert, E.P.: MAGNEX: A Text Editor for the Visually Impaired. In: Proc. of the ACM sixteenth annual conference on Computer science, 402-407 (1998)

7. Sjostrom, C.: Using Haptics in Computer Interfaces for Blind People. Retrieved (November, 2006), from http://certec.lth.se/doc/usinghapticsin/usinghapticsin.pdf

8. Sjostrom, C.: Non-Visual Haptic Interaction Design. Certec (2002)

9. Miller, T., Zeleznik, R.: An Insidious Haptic Invasion: Adding Force Feedback to the X Desktop. ACM, New York (1998)

10. Ramstein, C., Martial, O., Dufresne, A., Carignan, M., Chasse, P., Mabilleau, P.: Touching and Hearing GUI's Design Issues for the PC-Access System. ASSETS (1996)

11. Nam, C.S., Shafieloo, I.: Haptic Virtual Environments as a Tool to Support Learning in Science Education: A Preliminary Study. In: Proc. of the IASTED International Conference on Educational Technology, pp. 40-44 (2006)

12. Kumar, D.D., Ramasamy, R., Stefanich, G.P.: Science for Students with Visual Impairments: Teaching Suggestions and Policy Implications for Secondary Educators. Electronic Journal of Science Education, vol. 5(3) (2001)

13. Patton, J.R., Polloway, E., Cronin, M.: A Survey of Special Education Teachers Relative to Science for the Handicapped. Unpublished manuscript. University of Hawaii, Honolulu (1990)

14. Nam, C.S., Chung, D.: The Influences of Haptic Thermal Feedback on Object Identification and Perceived Presence. In: Proc. of the 16th World Congress of the International Ergonomics Association (IEA), IEA Press, Maastricht, Netherlands (2006)

15. Yu, W., Ramloll, R., Brewster, S.: Haptic Graphs for Blind Computer Users. In: Proc. of the First Workshop on Haptic Human-Computer Interaction, pp. 102-107 (2000) 